\title{
Free operant measurement of taste preferences in prosimian primates*
}

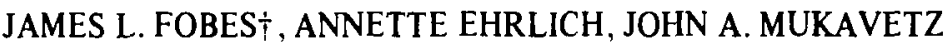 \\ and JORGE RODRIGUEZ-SIERRA \\ California State University, Los Angeles, California 90032
}

\begin{abstract}
The sucrose preferences of two prosimian primate species, slow loris and greater galago, were determined under aperiodic reinforcement of a free operant. Stimuli were solutions of the following concentrations: $5 \%, 10 \%, 20 \%, 30 \%$, and $40 \%$. Solutions of intermediate concentration were preferred, and thus the function relating barpresses to concentrations was nonmonotonic.
\end{abstract}

Although the behavior of nonhuman anthropoid primates (monkeys and apes) has been investigated extensively in recent years, we still know relatively little about those species that belong to the most primitive group of primates, the prosimians (tarsiers, lemurs, galagos. lorises, pottos). For this reason, a research program, which was aimed specifically at filling this need. was initiated some years ago by the second author. The broad goal was to furnish the kind of detailed information about prosimians that would make it possible, ultimately, to effect meaningful comparisons between them and anthropoid primates. Two species were selected for study, the African greater galago and the Asian slow loris. Both are nocturnal and are thickly furred arboreal animals. Unlike many other prosimian species, they are readily maintained in the laboratory, and this factor was critical in the decision to work with these particular species. A further consideration had to do with the secondary aim of the research program, which was to investigate variability among prosimian primates. It seemed important to avoid premature generalizations about all prosimians based on study of a single species. Consequently, two species were selected which, although closely related phylogenetically (both belong to the infraorder Lorisiformes) and similar with respect to brain morphology, diet, and natural habitat, are nevertheless obviously different behaviorally even to the casual observer (the galago is a rapid leaper and the loris a slow crawler).

Bringing new species into the laboratory poses certain problems; in particular, if one is interested in studying learning rather than naturally occurring behavior, there is a real need for background information about sensory-motor capacities and about the kinds of stimuli that can serve as reinforcers. The present experiment, like several previous ones (Ehrlich, 1968a, b, 1969;

\footnotetext{
*This research was supported in part by National Institutes of Health Grant MH 19196-01 to the second author.

$\div$ Present address is Department of Psychology. University of Arizona, Tucson, Arizona 85721.
}

Fobes, Ehrlich, \& Williams, 1971), is addressed to this issue. In it, measures of the responsiveness of both species to sucrose solutions of varying concentrations were obtained. So as to facilitate comparisons with anthropoid primates, test conditions were similar to those employed by other Es who have studied taste preferences in rhesus (Schrier, 1963, 1965) and in squirrel monkeys (Ganchrow \& Fisher, 1968).

\section{METHOD}

\section{Subjects}

The Ss were four greater galagos (Galago crassicaudatus) and four slow lorises (Nycticebus coucang). All were adults and had been in the laboratory for at least 1 year. All had previously learned to barpress for food and were trained readily to press for liquid reinforcement on a continuous reinforcement schedule. Mean weights of the two groups at the start of the experiment were: lorises $-1,019 \mathrm{~g}$, and galagos $-1,159 \mathrm{~g}$. Ss were maintained on a diet of Purina Monkey Chow pellets supplemented by small quantities of fruit, mealworms, milk, and cheese and were fed in the home cage once each day $1 \mathrm{~h}$ after testing. Water always was available in the home cage.

Both species were maintained on a reversed light cycle. During the light part of the cycle $(8 \mathrm{p} . \mathrm{m}$. to $8 \mathrm{a} . \mathrm{m}$.), white overhead room lights were on; during the dark part of the cycle, a shielded $100-\mathrm{W}$ red light was on. Behavioral tests were conducted between the hours of $10 \mathrm{a} . \mathrm{m}$. and 4 p.m., during the dark part of the cycle.

\section{Apparatus}

A nimals were tested in a standard primate test chamber which was placed inside a sound-deadened cubicle (both made by Lehigh Valley). Movements of the animal within the test chamber were restricted to an area $30 \mathrm{~cm}$ cubed in size. On one wall of the test chamber, the following were mounted: (1) the manipulandum -a bar $2.5 \mathrm{~cm}$ long and $16.5 \mathrm{~cm}$ above the floor; it required a force of $20 \mathrm{~g}$ to depress it; and (2) a liquid reinforcement delivery receptacle. The end of the bar and the liquid receptacle were $3.2 \mathrm{~cm}$ apart. The amount of fluid delivered was controlled by a liquid solenoid valve. A dim white light $(0.5 \mathrm{~W})$ illuminated the test chamber. Reinforcement contingencies were programmed by means of a tape puller. Responses were recorded in two ways: (1) a digital counter registered the total number of responses made during the entire 1-h session; and (2) each response caused a small deflection on an ink-writing chart recorder (Esterline-Angus). This provided a 
Table 1

Mean Number of Barpresses to Each Concentration

\begin{tabular}{|c|c|c|c|c|c|}
\hline \multirow[b]{2}{*}{ Species } & \multicolumn{5}{|c|}{ Percent Sucrose Concentration } \\
\hline & 5 & 10 & 20 & 30 & 40 \\
\hline $\begin{array}{l}\text { Lorises } \\
\text { Galagos }\end{array}$ & $\begin{array}{r}1136 \\
441\end{array}$ & $\begin{array}{r}1186 \\
642\end{array}$ & $\begin{array}{r}1309 \\
985\end{array}$ & $\begin{array}{r}1478 \\
614\end{array}$ & $\begin{array}{r}1168 \\
504\end{array}$ \\
\hline
\end{tabular}

continuous record of the distribution of responses within the test session and made it possible to compare the number of responses made during successive 10 -min segments of the session.

\section{Procedure}

As already noted, a deliberate attempt was made to obtain data that would be comparable to those of other operant studies of sucrose reinforcement in primates (Schrier, 1963, 1965; Ganchrow \& Fisher, 1968). Accordingly, (1) five concentrations of sucrose were used-5\%,10\%,20\%,30\%, and 40\%-and these were prepared by mixing anhydrous sucrose $\left(\mathrm{C}_{12} \mathrm{H}_{22} \mathrm{O}_{11}\right)$ with distilled water according to the weight-volume method (Pfaffman, Young, Dethier, Richter, \& Stellar, 1954). (2) Only one solution was presented each day, and test sessions lasted for $1 \mathrm{~h}$. (3) Reinforcement was available on an aperiodic schedule. No matter how often the animal pressed, it received reinforcement, on the average, every $35 \mathrm{sec}$. The actual range was $10-60 \mathrm{sec}$, in steps of $10 \mathrm{sec}$. (4) A reinforced barpress delivered a fixed amount of solution, $0.32 \mathrm{ml}$, regardless of the duration of the barpress. The experiment was preceded by a 5-day pretraining period, the purpose of which was to give the animals some experience in pressing for each of the five solutions and to allow the barpressing rate to stabilize. Each of the five solutions was presented once during this pretraining period, and the order of presentation was random. During the experiment, each of the five solutions was presented on three separate occasions, and again, the order of presentation was random, within each of three 5-day blocks for each S. Ss were tested for a total of 15 days.

\section{RESULTS}

The relationship between response rate and concentration is shown for each species separately in Table 1. Note that the highest response rates were for solutions in the middle range and the lowest response rates were for solutions that were extremely high or low in concentration. The scores shown in this table were subjected to a 2 by 5 mixed-design analysis of variance with two main effects (species and concentrations) and one interaction term (Species by Concentration). (1) Species effect: The $F$ value $(4.23, \mathrm{df}=1 / 6, \mathrm{p}<.09)$ came close to, but did not attain, an acceptable level of significance. However, there was a clear trend, as shown in the table, for lorises to respond more than galagos at all concentrations. The total number of responses over all sessions and concentrations was 12.741 for galagos and 25,101 for lorises. (2) Concentration effect: For all animals combined, responses to the various concentrations were unequal $(F=7.14$, df $=4 / 24$, $\mathrm{p}<.01$ ). (3) Species by Concentration interaction: Lorises responded most frequently when the $30 \%$ solution was available, and galagos responded most frequently when the $20 \%$ solution was available ( $F=$ $3.24, \mathrm{df}=4 / 24, \mathrm{p}<.05$ ).

Changes in response rate occurred not only as a function of species and of concentration, but also as a function of repeated testing, both within and between sessions. As shown in Table 2, the changes were similar in both species. One of the outcomes shown in this table is the mean number of presses made by each species during 10-min segments of the $1-\mathrm{h}$ sessions. The data for all 15 days of testing were pooled, but it should be noted that this was done for ease of presentation only and that the same trends were apparent at each concentration. For all animals, there were significantly fewer responses during the second $30 \mathrm{~min}$ of a session than during the first 30 min (mean difference $=353.3$, correlated $\mathrm{t}=2.52$, $\mathrm{df}=7, \mathrm{p}<05$ ), but the effect was more marked in galagos.

Also shown in Table 2 is the effect of three separate (but nonsuccessive) presentations of the same concentration. Again, because the trends were similar, data were pooled for all concentrations and the mean number of barpresses made by each species on first, second, and third presentations is shown. For all animals, there were significantly fewer responses on the third presentation than on the first (mean difference $=$ 404.5 , correlated $t=2.43, \mathrm{df}=7, \mathrm{p}<.05$ ), and the rate of decline was similar in both species.

Table 2 also shows, in blocks of 5 days, the mean number of responses made by each species during the 15 days of testing. There was virtually no change among galagos, and lorises decreased slightly. However, whether computed for the group as a whole or for each species separately, the difference between the first and last block of 5 days was not statistically significant.

\section{DISCUSSION}

The present results are substantially in agreement with those of an earlier experiment (Fobes \& Ehrlich, 1971) in which glucose preferences of the same two species were measured by a paired comparison technique in the home cage. Both studies indicate that lorises prefer sweeter solutions than do galagos. In the previous

Table 2

Mean Number of Barpresses During Six Consecutive 10-Min Segments, to Three Presentations, and Across Days

\begin{tabular}{|c|c|c|c|c|c|c|c|c|c|c|c|c|}
\hline \multirow[b]{2}{*}{ Species } & \multicolumn{6}{|c|}{ 10-Min Segments } & \multicolumn{3}{|c|}{ Presenta,ions } & \multicolumn{3}{|c|}{ Days } \\
\hline & 1 & 2 & 3 & 4 & 5 & 6 & 1 & 2 & 3 & $1-5$ & $6-10$ & $11-15$ \\
\hline $\begin{array}{l}\text { Lorises } \\
\text { Galagos }\end{array}$ & $\begin{array}{r}1020 \\
648\end{array}$ & $\begin{array}{r}1111 \\
651\end{array}$ & $\begin{array}{r}1082 \\
573\end{array}$ & $\begin{array}{r}1048 \\
494\end{array}$ & $\begin{array}{r}1012 \\
438\end{array}$ & $\begin{array}{r}1003 \\
382\end{array}$ & $\begin{array}{l}2288 \\
1231\end{array}$ & $\begin{array}{l}2154 \\
1079\end{array}$ & $\begin{array}{r}1834 \\
876\end{array}$ & $\begin{array}{l}2287 \\
1248\end{array}$ & $\begin{array}{l}2171 \\
1338\end{array}$ & $\begin{array}{l}1817 \\
1259\end{array}$ \\
\hline
\end{tabular}


experiment. lorises drank significantly more than did galagos at all concentrations. Here, although the effect did not quite reach an acceptable level of significance, there was a definite tendency for lorises to press more than galagos at all concentrations. Similarly, in the previous experiment, lorises preferred a more concentrated solution than did galagos; the same effect was found here, and, in both experiments, the effect was significant. The actual solutions preferred shifted, however. Sweeter solutions were chosen in this experiment (galagos shifted from $10 \%$ to $20 \%$ and lorises from $20 \%$ to $30 \%$ ), but whether the change resulted from the change in reinforcer (glucose to sucrose) or from the change in method (ingestion to barpressing) is not clear.

Like anthropoid primates, prosimians press at a high rate for sucrose solutions. However, so far as preferences for particular solutions is concerned, prosimians apparently differ from other primates. Rhesus (Schrier, 1963, 1965) and squirrel monkeys (Ganchrow \& Fisher, 1968) barpressing for sucrose on an aperiodic basis and like the prosimian species tested here, receiving less than $1 \mathrm{ml}$ of solution for each rewarded barpress increase their rates of response as the concentration of the rewarding solution is increased. The only situation in which anthropoid primates reveal a preference for solutions of intermediate concentration is one in which the volume of reward is greatly increased, e.g., each rewarded press delivers $1 \mathrm{ml}$ or more (Conrad \& Sidman, 1956) or reinforcement is on a one-for-one basis (CRF) with barpresses (Schrier, 1965). The possibility, suggested by the present data, that taste preferences of anthropoid and prosimian primates differ deserves to be investigated further.

Because changes in response rate can occur with repeated testing, the experiment was designed so that the various solutions were presented randomly within three 5-day blocks during the 15-day test period. After the experiment, the data were examined to see whether systematic changes had occurred either within or between sessions. Response rate declined significantly both within sessions and between nonsuccessive presentations of the same solution. A similar within-sessions decline was reported by Schrier (1965) in rhesus monkeys barpressing for sucrose. It should be noted, though, that in the present experiment, these within- and between-sessions declines were a function of repeated presentations of the same stimulus. No significant decline occurred over the entire 15-day sequence in either species, and thus systematic changes in responding due to repeated testing do not account for the preference functions reported here.

\section{REFERENCES}

Conrad, D. G., \& Sidman, M. Sucrose concentration as reinforcement for lever pressing by monkeys. Psychological Reports, 1956, 2, 381-384.

Ehrlich, A. Food-motivated behavior in prosimians. Folia Primatologica, 1968a, 8, 66-71.

Ehrlich, A. Activity levels in prosimians. Folia Primatologica, 1968b, 8, 72-76.

Ehrlich, A. Behavioral characteristics of the slow loris, galago, and rhesus monkey. In C. R. Carpenter (Ed.), Proceedings Second International Congress Primatology: Behavior. Vol. I. Basel: S. Karger, 1969. Pp. 119-127.

Fobes, J. L., \& Ehrlich, A. Glucose preferences in the greater galago (Galago crassicaudatus) and slow loris (Nycticebus coucang). Folia Primatologica, 1971, 16, 306-311.

Fobes, J. L., Ehrlich, A., \& Williams, K. Rear projection visual discrimination apparatus for prosimians. Laboratory Primate Newsletter, 1971, 10, 7-8.

Ganchrow, J., \& Fisher, G. L. Two behavioral measures of the squirrel monkey's (Saimiri sciureus) taste for four concentrations of five sugars. Psychological Reports, 1968, 22, 503-511.

Pfaffman, C., Young, P. T., Dethier, V. G., Richter, C. P., \& Stellar, E. The preparation of solutions for research in chemoreception and food acceptance. Journal of Comparative \& Physiological Psychology, 1954, 47, 93-96.

Schrier, A. M. Sucrose concentration and response rates of monkeys. Psychological Reports, 1963, 12, 666.

Schrier, A. M. Response rates of monkeys (Macaca mulatta) under varying conditions of sucrose reinforcement. Journal of Comparative \& Physiological Psychology, 1965, 59, 378-384.

(Received for publication July 28, 1972: revision received November 16,1972 .) 